\title{
"O Toque de Billy": formação, influências, obras e estilo composicional de Billy Strayhorn
}

\author{
J. William Murray (Towson University, Towson, EUA) \\ jwilliammurray@comcast.net \\ Tradução de Fausto Borém (UFMG, Belo Horizonte, MG) \\ fborem@ufmg.br
}

Resumo: Estudo estilistico sobre a música do compositor e pianista norte-americano Billy Strayhorn, que se tornou o braço-direito e alter ego de Duke Ellington. Discute o processo único de colaboração composicional entre estes dois gigantes do jazz e a questão da autoria no repertório da Duke Ellington Orchestra. Inclui o contexto da formação musical de Strayhorn e de suas obras. A análise de 19 obras selecionadas de Billy Strayhorn revela características estilísticas relacionadas ao estilo-andamento, métrica, tonalidade, forma, duração, ritmo harmônico, linguagem harmônica e outros detalhes relevantes.

Palavras chave: Billy Strayhorn e Duke Ellington; autoria e colaboração composicional; análise musical do jazz; influência entre música erudita e popular; cromatismo no jazz.

\section{"Billy's touch": background, influences, works and compositional style of Billy Strayhorn}

Abstract: Style study on the music of American composer and pianist Billy Strayhorn who became Duke Ellington's right arm and alter ego. It discusses the unique compositional collaboration between the two giants of jazz and the question of authorship in the Duke Ellington Orchestra repertory. It includes a historical context of Strayhorn's musical background and his works. The analysis of 19 selected works of Billy Strayhorn reveals traits related to style/tempo, time signature, tonality, form, length, harmonic chord pace and harmonic language and some other relevant details.

Keywords: Billy Strayhorn and Duke Ellington; authorship and compositional collaboration; musical analysis of jazz; influence between classical and popular music; chromaticism in jazz.

\section{1 - Introdução}

0 ato de compor geralmente inclui ressonâncias das músicas de outros compositores, em elementos que incluem desde fundamentos teóricos e procedimentos composicionais mais técnicos até práticas de performance e improvisação, especialmente no âmbito do jazz. Além da influência que se verifica por meio do processo de escuta, traços de outros compositores são absorvidos ao se estudar uma obra, analisá-la, transcrevê-la ou arranjá-la.

No meu caso (MURRAY, 2011), dois compositores me marcaram como modelos composicionais: Bill Evans (1929-1980) e Billy Strayhorn (1915-1967). Nesse estudo, proponho levantar as características composicionais de Billy Strayhorn (veja estudo estilístico sobre a música de Bill Evans às p.21-34 do volume 28 de Per Musi). Para isso, considero apenas as composições de Strayhorn que aparecem em fake books legalmente publicados, que são fontes primárias relevantes do repertório do jazz.

Strayhorn é creditado como autor de centenas de composições. A maioria das quais resulta de sua intensa colaboração com a orquestra de Duke Ellington, o que dificulta verificar a real autoria das obras. Muitas vezes Strayhorn e Ellington recebem crédito como compositores da mesma música. Todas as 19 canções de Strayhorn aqui selecionadas (veja Exs.1 e 2 abaixo) são conhecidas como sendo somente de sua autoria, embora possa existir duplicidade quanto à questão de direitos autorais. Apenas duas delas - Lush life e My little brown book - foram escritas antes de Strayhorn ter entrado para o grupo de Ellington, em 1938. 


\section{2 - A formação de Billy Strayhorn}

Durante a maior parte de sua carreira, Billy Strayhorn esteve muito próximo de Duke Ellington, mas o primeiro geralmente é lembrado como simples assistente do segundo. Na verdade, Strayhorn escreveu, arranjou ou revisou cerca de $40 \%$ do repertório do band leader no período de 1939 a 1967 (VAN DE LEUR, 1999, p.1081), que o considerava seu braço direito:

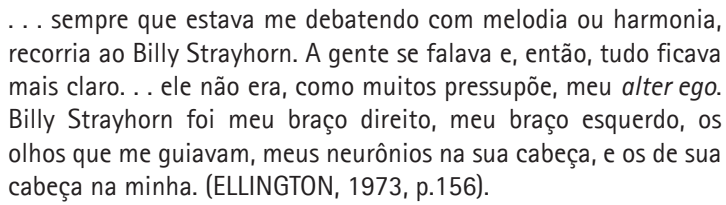

Essa grande associação com Ellington se tornou um obstáculo para que Strayhorn recebesse crédito como compositor, função à qual ele se dedicou intensamente. Entretanto, ele parecia satisfeito em permanecer nos bastidores e deixar todos os créditos para Ellington, quem, independentemente dessa colaboração, ainda seria considerado um dos grandes compositores norteamericanos de todos os tempos.

Nos últimos anos, pesquisas sobre o trabalho de Strayhorn o consolidam como importante compositor e arranjador. Uma das questões que têm surgido é se a orquestra de Ellington seria a mesma sem as contribuições de Billy Strayhorn. Para Billy REED (2010, p.95), no seu livro Hot from Harlem, a lenda de Ellington tal qual nós conhecemos, sem Strayhorn, provavelmente não existiria. Por outro lado, críticos com James Lincoln Collier e Leonard Feather discordam ligeiramente deste ponto de vista. Andrew Homzy, Professor Associado e pesquisador da Concordia University em Montreal, diz que a relação entre Strayhorn e Ellington era semelhante à relação entre Haydn e Mozart, "na qual, primeiro, o mestre estabelece o estilo e, depois, o mais jovem o absorve, o expande e o leva a outras direções e, finalmente, com a morte do mais jovem, o mais velho retoma os ensinamentos deixados por este (CARNER, 1991, p.51). De toda maneira, cada vez mais, críticos e pesquisadores têm reconhecido o valor de Strayhorn para a Duke Ellington Orchestra.

\section{3 - Influências sobre Billy Strayhorn}

Billy Strayhorn cresceu em uma vizinhança pobre de Pittisburgh, Pennnsylvania, em uma casa sem eletricidade ou rua pavimentada (VAN DE LEUR, 1999, p.1081). Desde cedo, se interessou por música, mas sua família não tinha dinheiro para the comprar qualquer instrumento musical. Para comprar um piano, ainda na época da escola elementar, ele começou a vender jornais na esquina da Pennfield Drugs. Empregou-se nesta farmácia e, ajuntando seu salário, pôde comprar seu piano pagar e suas aulas de música nesse instrumento antes de completar os estudos elementares. 0 amigo de infância Robert Conaway lembra que Strayhorn gastava todo o dinheiro ganho comprando músicas de todos os tipos, com as quais, em um canto da casa, construiu uma pilha de um metro e meio de altura (HAIDU, 1996, p.12).
Com o instrumento em casa, estudava freneticamente: ". . . comecei a estudar e, quanto mais aprendia, mais eu queria aprender" (Strayhorn, citado por HAIDU, 1996, p.11).

Strayhorn frequentou a escola Westinhouse High, financiada por George Westinhouse, da Westinhouse Company. Essa escola tinha uma swing band, mas ele estava mais interessado em ser um concertista. Por isso, se concentrou na música dos pianistas eruditos (HAIDU, 1996, p.14). Ainda na high school, teve aulas de piano erudito e harmonia e se tornou o pianista da Westinhouse High Senior Orchestra. Depois de ouvi-lo tocar o Concerto para Piano em Lá Menor Op.16, de E. Grieg, o maestro da banda da escola, Carl McVicker, comentou que ". . . a orquestra era um grupo de alunos, mas Billy Strayhorn era um artista profissional" (HAIDU, 1996, p.15).

Nesse periodo, Strayhorn começou a compor. A peça Valse, com suas linhas melódicas ondulantes e graciosas modulações, e que foi estreada com a Westinghouse Orchestra Club, já exibia o estilo de suas futuras composições. Nela, ele utiliza transitava entre tons menores à maneira de Chopin (HAIDU, 1996, p.16). Ainda nesse período, para sua graduação, escreveu uma peça chamada Concerto for piano and percussion, fortemente influenciada por Gershwin, com orquestração completa, com partes para todos os instrumentos. Na sua estreia, muitos alunos da escola pensaram que estavam ouvindo a Rhapsody in blue de Gershwin (HAIDU, 1996, p.17). Mas a peça também aponta para alguns elementos musicais que apareceriam mais tarde na obra de Strayhorn: variações de frases no estilo da música popular sobre harmonias cromáticas, ritmos sincopados, padrões rítmicos repetidos, hemíolas e a utilização recorrente do acorde menor com sétima maior (HAIDU, 1996, p.17).

Strayhorn queria iniciar seus estudos de música em uma universidade, mas não foi em frente. Seu amigo Henry Henforth comenta:

Billy procurou algumas faculdades, mas foi desestimulado devido à sua cor e às dificuldades de obter auxílio financeiro. A própria ideia de um pianista concertista negro era impensável. Não tinha nada a ver com o considerável talento de Billy (VAN DE LEUR, 2002, p.6.).

Ao mesmo tempo em que continuou trabalhando na farmácia após sua graduação, Strayhorn continuou tocando na escola de $2^{\circ}$ grau e montou um musical chamado Fantastic rhythm, o qual incluía um coral de dançarinas e uma pequena banda, que ele mesmo dirigia. Todas as 10 canções e suas letras foram escritas por Strayhorn, entre elas My little brown book, que mais tarde se tornaria famosa quando foi gravada pela Duke Ellington Orchestra. Seus arranjos para uma orquestra com 12 componentes já refletia seu futuro estilo. As críticas positivas tiveram repercussão na área de Pittsburgh e alavancou a reputação local de Strayhorn.

Ainda esperançoso de seguir a carreira como músico erudito, Strayhorn frequentou o Pittsburgh Musical Institute em 
1936, estudando piano e teoria musical por dois meses, mas desistiu após a morte súbita de seu professor, Charles Boyd, quem, de acordo com Strayhorn, foi seu melhor professor (VAN DE LEUR, 2002, p.18). Reconheceu que as oportunidades para um concertista negro eram ínfimas $e_{\text {, }}$ por isso, concentrou seus esforços no jazz e nas canções de teatro musical. Nesse período, compôs Lush life, uma de suas mais famosas peças, na qual demonstrou sua afinidade com uma música altamente cromática.

\section{4 - Billy Strayhorn e a Duke Ellington Orchestra}

0 acontecimento mais importante na carreira de Strayhorn ocorreu em dezembro de 1938, quando um amigo agendou um encontro com Duke Ellington nos bastidores do Stanley Theater em Pittsburgh. Resultou dai uma colaboração de 28 anos que mudou a história do jazz por várias razões. Ellington, incerto de que tarefas designaria a Strayhorn, o contratou inicialmente para escrever letras de música. Rapidamente, isso deu lugar à tarefa de arranjar, de criar novas composições e, em última instância, ao estabelecimento de uma colaboração entre dois músicos única na história da música.

Ellington sofreu um grande baque em 1941, durante um conflito entre a ASCAP (American Society of Composers and Publishers) e a rede de rádios. As rádios se recusaram a transmitir músicas de qualquer membro da $A S C A P, 0$ que significava que de suas composições estaria no ar. Necessitando de um repertório que pudesse ser tocado e transmitido radiofonicamente, Ellington pediu a seu filho Mercer e a Strayhorn para comporem novas peças pois, pelo fato de não serem membros da ASCAP, poderiam ser gravadas. Foi durante este período que Strayhorn compôs a maioria de suas canções mais conhecidas, entre elas Take the A Train, Chelsea Bridge, Clementine, A Flower is a lovesome thing, After all, Love like this can't last e Rain check(VAN DE LEUR, 2002, p.45). Chelsea Bridge se tornou a primeira peça de Strayhorn a atrair a atenção do grande público. Já Take the A Train se tornou uma de suas mais famosas e gravadas músicas, se tornando, eventualmente, o tema de identificação da Duke Ellington Orchestra.

Strayhorn continuou a compor e arranjar para a Duke Ellington Orchestra até o final de sua vida. Colaborou com Ellington em todos os tipos de música, desde peças para a Broadway até obras religiosas e de longa duração. Também buscou iniciativas independentes, compondo e arranjando sem a tutela de Ellington, com graus de sucesso variados. Mas, no fundo, sentia que o seu caminho era trabalhar para Ellington. Fumante e alcoólatra, Strayhorn foi diagnosticado com câncer de esôfago em 1964. Sua saúde piorou nos anos seguintes até que veio a falecer em 31 de maio de 1967, aos 51 anos. Durante os últimos meses de vida, Strayhorn completou outra de suas canções conhecidas: Blood count [Exame de sangue], que é considerada sua última composição. A escolha de uma tonalidade menor para esta peça meditativa revela uma prática composicional pouco comum na música de Strayhorn. Autobiográfica, se constitui em uma metáfora musical que expressa abertamente seus sentimentos de tristeza, frustração e derrota (VAN DE LEUR, 2002, p.171).

A morte de Strayhorn foi um grande impacto para Duke Ellington, que expressou seus sentimentos na elegia que proferiu no funeral, deixando claro para todos sua admiração e gratidão. Alguns meses mais tarde, a Duke Ellington Orchestra gravou o álbum And his mother called him Billy, que contem diversas canções conhecidas de Strayhorn. A última faixa do disco é Lotus blossom com Ellington ao piano, gravada sem que este soubesse que os microfones estavam ligados, pois a sessão de gravação já havia terminado. Esta performance de Ellington, ao mesmo tempo solene, íntima e atormentada, impregnada de notas atropeladas e ruídos de estúdio desempenha 0 papel de uma coda, fechando o disco (HAIDU, 1996, p.261). Ellington se recuperou da perda do amigo e colega de profissão, continuou a turnê e retomou o ofício de compor com mais ímpeto: "Estou escrevendo mais do que nunca. Tenho que fazer isto. Billy Strayhorn deixou, na dormência de sua falta, um grande vazio" (HAIDU, 1996, p.261).

Strayhorn foi um autodidata genial. Não há dúvidas de que sua longa associação com Ellington, hoje considerado um dos maiores compositores norte-americanos de todos os tempos, foi um grande aprendizado. Mas ele também tinha o que ensinar a Ellington. Sua colaboração, com raízes na música erudita, permitiu a seu mestre encontrar conforto, apoio e cooperação no seu desejo de combinar suas ambições eruditas e populares em um mesmo ambiente: o jazz (GIDDINS e DE VEAUX, 2009, p. 236). As composições de Strayhorn estão entre as mais sofisticadas peças do repertório jazzístico, tanto do ponto de vista estrutural quanto harmônico. Com Ellington, sua música fundiu técnicas composicionais da música erudita europeia com conceitos do jazz firmemente ancorados na herança afro-norte americana (VAN DE LEUR, 1999, p.1082). Suas composições anteciparam o papel que as orquestrações no estilo cool jazz de Gil Evans e Gerry Mulligan tiveram na música de Miles Davis no final da década de 1940, assim como também antecipou o movimento third stream da década de 1950. Sua música também foi referencial para outros notáveis do jazz como Dizzy Gillespie, John Lewis, Benny Carter, Slide Hampton, Billy May, Bill Finnegan e Ralph Burns (VAN DE LEUR, 1999, p.1082).

Comentários destes músicos mostram o impacto de Strayhorn na comunidade do jazz. Gill Evans disse que após ouvir Chelsea Bridge, tudo o que passou a fazer era imitar Strayhorn (VAN DE LEUR, 1999, p.1083). Para Benny Carter, a música de Strayhorn era completa, indo muito além de apenas riffs e progressões harmônicas, obrigando os colegas que a ouvia a repensar, de certa maneira, o que estavam fazendo (HAIDU, 1996, p.87). Gerry Mulligan comentou que mesmo com tanta sofisticação, a música de Strayhorn não soava complicada, mas sim completamente natural e emotiva (HAIDU, 1996, p.87). De acordo com Willie Ruff, Strayhorn não perdia tempo com clichês e sempre surpreendia já na 
primeira audição (HAIDU, 1996, p.239). Lawrence Brown, membro da Duke Ellington Orchestra por muito tempo, disse que Strayhorn foi um dos músicos mais notáveis e subestimados que conheceu e sentia que a profundidade de sua música era o que, por trás, ancorava todo o grupo (NICHOLSON, 1999, p.202).

A orientação composicional mais importante para Strayhorn era o que chamava de "pensar com os ouvidos", pois colocava grande ênfase no resultado sonoro, na expressão das emoções, ao invés de se preocupar com questões teóricas da música (VAN DE LEUR, 2002, p.67). A música deveria sempre soar bem. Em uma entrevista a Bill COSS (1993, p.501-502) em 1962, ao falar sobre sua maneira de compor e arranjar, ele disse:

Tenho uma regra geral sobre escrever. Rimsky-Korsakov dizia: todas as partes devem ser fáceis para os dedos. Esta é minha primeira regra: escrever algo que possa ser tocado. Caso contrário, nunca será natural, ou maravilhoso, como algo que encaixa nos seus dedos. . . você precisa encontrar o colorido certo. . . a cor é o que ela é, e você sabe quando a encontra.

\section{5 - 0 Estilo composicional de Billy Strayhorn}

A tabela do Ex.1 traz os títulos e os seguintes elementos das 19 obras selecionadas de Strayhorn no presente estudo: (1) título, (2) gravação mais antiga da peça ou copyright, (3) estilo/andamento, (4) métrica, (5) tonalidade, (6) forma, (7) duração e (8) ritmo harmônico. Já a tabela do Ex.2 traz (1) a linguagem harmônica de cada peça e (2) um resumo das características principais de cada peça.

Os especialistas concordam que as características composicionais de Strayhorn diferem das de Duke Ellington, mesmo que seus trabalhos estivessem tão intimamente ligados e que compusessem peças em parceria. Embora essas diferenças não sejam objeto do presente estudo, tornam-se um elemento complicador na análise da obra de Strayhorn. Por isso, apenas as obras compostas especificamente por Strayhorn e que estão incluidas em fake books serão aqui consideradas.

Outro complicador é que Strayhorn planejou a maioria de suas composições ou para um combo de pequena instrumentação ou para uma big band. Como ele era um grande arranjador, analisar apenas suas leadsheets em busca de traços composicionais pode conduzir ao erro. Ao compor, Strayhorn imaginava como a peça soaria naquele grupo especifico de instrumentistas para o qual trabalharia e, assim, direcionava seu arranjo. A leadsheet era apenas um ponto de partida para o arranjo, como ele próprio dizia (STRAYHORN, 1942, p.27):

\footnotetext{
Arranjadores e compositores deveriam ver a peça que estão trabalhando como uma entidade autônoma. Deveriam utilizar quatro ou cinco dimensões e enxergar este material como um todo por cima, por baixo e dos lados. Então, o trabalho torna-se transpor a imagem física em uma imagem mental completa e integral. .. sou a favor do que chamo de 'pensar com ou ouvido' - novamente, eis aqui o sentido da intuição, o que não canso de enfatizar.
}

Embora a realização da música, já com toda a sua instrumentação definida, seja um paradigma na música de Strayhorn, por uma questão de escopo, nos restringiremos às leadsheets somente. Do mesmo modo, analisar um número restrito de obras pode levar a resultados não muito representativos. Por isso, optei por selecionar as obras nas quais percebo uma identificação com o que considero mais característico. De toda maneira, as obras aqui selecionadas coincidem também com o foco de muitos exemplos musicais utilizados na abrangente análise de Walter VAN DE LEUR (2002) em Something to live for: the music of Billy Strayhorn. Esta seleção também coincide com as listas de composições de Strayhorn mais gravadas por outros músicos (LORD, 2002, v.29, 30 e 31). Assim, podemos considerar a lista no Ex.3 como razoavelmente representativa. A maioria das canções dos fake books utilizadas na presente análise datam do início da carreira do compositor, e este foco coincide com o que ficou conhecido como "Billy touch" ("o toque de Strayhorn"), que marcou seu estilo emergente.

A tabela no Ex.4 mostra uma categorização das composições selecionadas por estilo ou andamento.

Do ponto de visto estilístico, as baladas de Strayhorn estão entre as suas composições mais conhecidas. Geralmente são mais sentimentais, muitas vezes chamadas de "mood pieces" e incluem Chelsea Bridge, Daydream, Passion flower, A Flower is a lovesome thing, Lush life e Lotus blossom. Embora não seja uma balada, Blood count também pode ser encaixada nessa categoria. A maioria de suas pecas incluídas nos fake books são em andamentos lentos ou moderados; up tempo não era o seu forte. Chama a atenção também o fato de não haver nenhum blues nesta lista. Embora Strayhorn tenha escrito várias peças no idioma e forma do blues, elas não se destacam no seu repertório (LAMBERT, 1999, p.283), pois ele se identificava muito mais com o mundo do show business sofisticado e dos nightclubs de alta classe (LAMBERT, 1999, p.278). Take the A train, uma de suas obras mais conhecidas (embora muitos ainda creditem Duke Ellington como seu compositor), é considerada atípica dentro de seu estilo composicional.

Um dos elementos mais notáveis nas composições de Strayhorn são suas melodias líricas e originais. Compor sob medida para um instrumentista foi uma das características que Strayhorn aprendeu com Duke Ellington. De fato, várias das obras aqui selecionadas foram escritas especificamente para o saxofonista alto Johnny Hodges.

Do ponto de vista da forma, a maioria maciça de suas peças segue a forma convencional $A A B A$, a exemplo de Tin Pan Alley, como mostra a tabela de ocorrência de esquemas formais no Ex.5. A maioria de suas peças segue o padrão de duração de 32 compassos dentro da forma $A A B A$, ou suas variações. $E$ é curioso observar que as exceções se encontram no seu período Pré-Duke Ellington. 


\begin{tabular}{|c|c|c|c|c|c|c|c|c|c|c|c|c|c|c|c|c|c|}
\hline 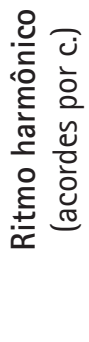 & 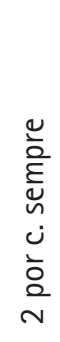 & 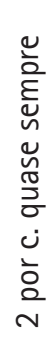 & 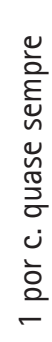 & $\begin{array}{l}\dot{u} \\
\text { à } \\
\text { N } \\
\text { ò } \\
-\end{array}$ & $\begin{array}{l}\dot{0} \\
\dot{a} \\
\stackrel{2}{2} \\
\sim \\
\text { ò } \\
-\end{array}$ & 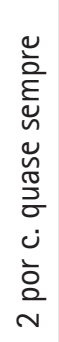 & 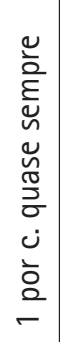 & 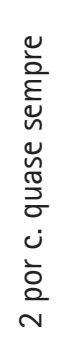 & 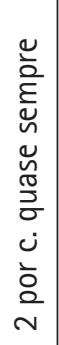 & $\begin{array}{l}\dot{v} \\
\dot{a} \\
\sim \\
\text { ż } \\
-\end{array}$ & 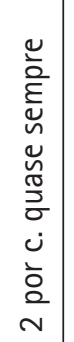 & $\begin{array}{l}\dot{u} \\
\dot{a} \\
o \\
\sim \\
\partial \\
-\end{array}$ & $\begin{array}{l}\dot{0} \\
\dot{a} \\
\stackrel{2}{0} \\
\text { zे } \\
-\end{array}$ & 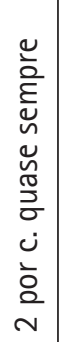 & 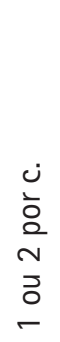 & 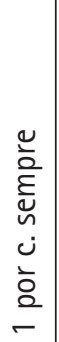 & $\begin{array}{l}\dot{u} \\
\dot{a} \\
\stackrel{2}{2} \\
\stackrel{0}{o} \\
-\end{array}$ \\
\hline 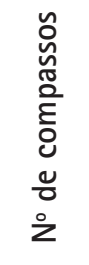 & లి & స్ & $\tilde{m}$ & ๗ే & $\approx$ & $\tilde{ల}$ & ๗ి & ల్ & 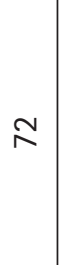 & రే & లి & $\stackrel{m}{m}$ & ల్ & ల్ & 우 & ల్ & ల్ \\
\hline $\begin{array}{l}\stackrel{\pi}{\xi} \\
\stackrel{\varpi}{\sqcup}\end{array}$ & 高 & 㐫 & 高 & 京 & 西 & 邑 & 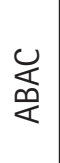 & 高 & $\begin{array}{l}\text { 这 } \\
\text { 这 }\end{array}$ & $\begin{array}{l}\text { 己ั } \\
\text { 这 }\end{array}$ & $\begin{array}{l}\frac{1}{\alpha} \\
\frac{1}{4}\end{array}$ & 髉 & $\underset{\frac{\alpha}{\alpha}}{\stackrel{\alpha}{<}}$ & $\begin{array}{l}\text { U⿳亠丷厂巾 } \\
\text { 产 }\end{array}$ & 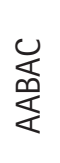 & 产 & 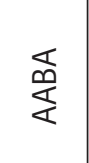 \\
\hline 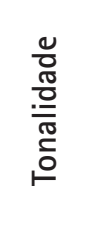 & 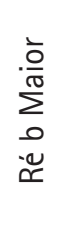 & $\sum_{\substack{\frac{0}{\pi} \\
\frac{\pi}{\pi}}}$ & 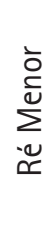 & 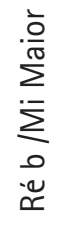 & $\begin{array}{l}\frac{\overline{0}}{\pi} \\
\sum_{0}^{\pi} \\
\overline{\bar{n}}\end{array}$ & 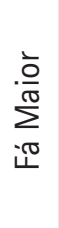 & 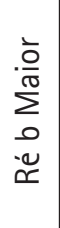 & 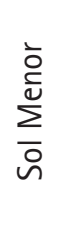 & $\begin{array}{l}\frac{\overline{0}}{\pi} \\
\sum_{0}^{\pi} \\
0 \\
i \bar{n}\end{array}$ & 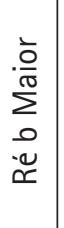 & $\begin{array}{l}\frac{\bar{\partial}}{\bar{\pi}} \\
\sum_{0}^{\pi} \\
\dot{0} \\
\bar{n}\end{array}$ & $\begin{array}{l}\frac{\bar{\partial}}{\pi} \\
\sum_{0}^{\pi} \\
\bar{i}\end{array}$ & $\begin{array}{l}\frac{\bar{o}}{\pi} \\
\frac{\pi}{\infty} \\
\sim\end{array}$ & $\begin{array}{l}\frac{\bar{\partial}}{\pi} \\
\sum^{\pi} \\
.0 \\
\dot{\Sigma}\end{array}$ & 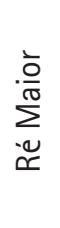 & 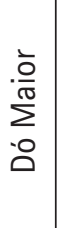 & 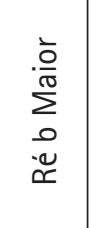 \\
\hline 茎 & $\frac{\partial}{\gamma}$ & $\frac{\partial}{\partial}$ & $\frac{\partial}{\partial}$ & $\frac{\partial}{\partial}$ & $\frac{\partial}{\gamma}$ & $\frac{d}{A}$ & $\frac{\partial}{f}$ & $\frac{\partial}{\partial}$ & $\frac{d}{\partial}$ & $\frac{d}{A}$ & $\frac{\partial}{\gamma}$ & $\frac{\partial}{\partial}$ & $\frac{d}{\partial}$ & $\frac{\partial}{\partial}$ & $\frac{\partial}{\gamma}$ & $\frac{\partial}{\gamma}$ & $\frac{\partial}{\gamma}$ \\
\hline 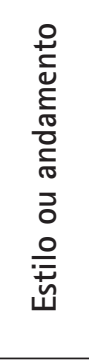 & $\begin{array}{l}\frac{\pi}{0} \\
\frac{\pi}{\pi} \\
\infty\end{array}$ & 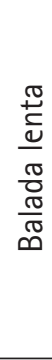 & 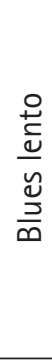 & $\begin{array}{l}\frac{\pi}{\sigma} \\
\frac{\pi}{\pi} \\
\infty\end{array}$ & 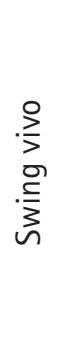 & $\begin{array}{l}\frac{\pi}{0} \\
\frac{\pi}{\pi} \\
\infty\end{array}$ & $\begin{array}{l}\frac{\pi}{c} \\
\frac{\pi}{\pi} \\
\infty\end{array}$ & 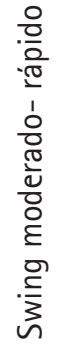 & 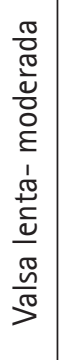 & 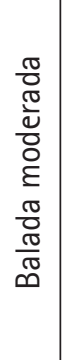 & 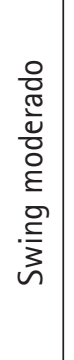 & $\begin{array}{l}\frac{\pi}{0} \\
\frac{\pi}{0} \\
\frac{\pi}{0} \\
0 \\
\frac{\delta}{\varepsilon} \\
\frac{\pi}{0} \\
\frac{\pi}{\pi} \\
\infty\end{array}$ & $\begin{array}{l}\frac{\pi}{0} \\
\frac{\pi}{\pi} \\
\infty\end{array}$ & $\begin{array}{l}\frac{0}{0} \\
\frac{0}{20} \\
\frac{0}{2} \\
\cdot \frac{\cdot}{3} \\
n\end{array}$ & 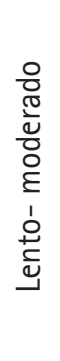 & $\begin{array}{l}\frac{0}{0} \\
\frac{\pi}{0} \\
\frac{0}{0} \\
\frac{0}{2}\end{array}$ & : \\
\hline 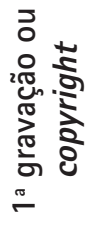 & $\underset{\sigma}{\sigma}$ & ฐ & $\begin{array}{l}\hat{6} \\
\stackrel{\sigma}{\sigma}\end{array}$ & $\underset{\sigma}{\sigma}$ & $\underset{\sigma}{\sigma}$ & 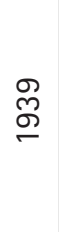 & む্ & ั & $\begin{array}{l}0 \\
\stackrel{+}{\sigma}\end{array}$ & $\frac{\mathscr{c}}{\stackrel{\tilde{\sigma}}{c}}$ & $\stackrel{\Xi}{\stackrel{\Xi}{\square}}$ & $\stackrel{\stackrel{\sim}{\sigma}}{\sigma}$ & $\underset{\sigma}{\sigma}$ & ฐ্ঠ & 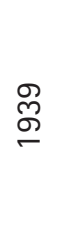 & 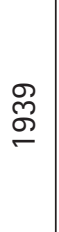 & ભ \\
\hline 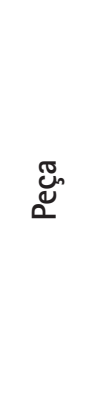 & 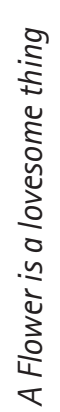 & 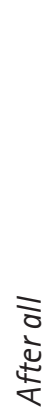 & $\begin{array}{l}\tilde{5} \\
0 \\
0 \\
0 \\
0 \\
\infty\end{array}$ & 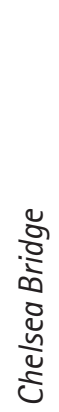 & 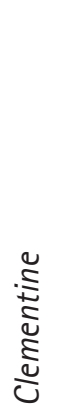 & 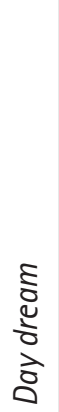 & $\begin{array}{l}\frac{\delta}{\delta} \\
\frac{\delta}{\delta} \\
\frac{\delta}{n}\end{array}$ & 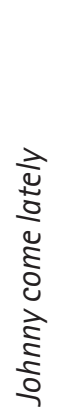 & 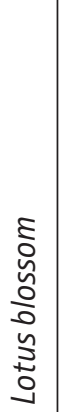 & 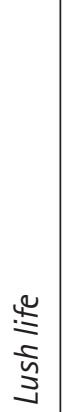 & 曹 & 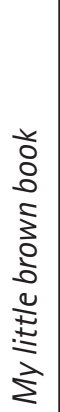 & 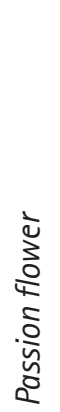 & 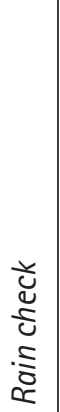 & 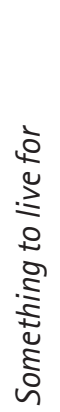 & 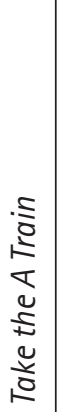 & 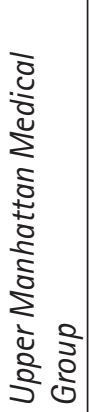 \\
\hline
\end{tabular}




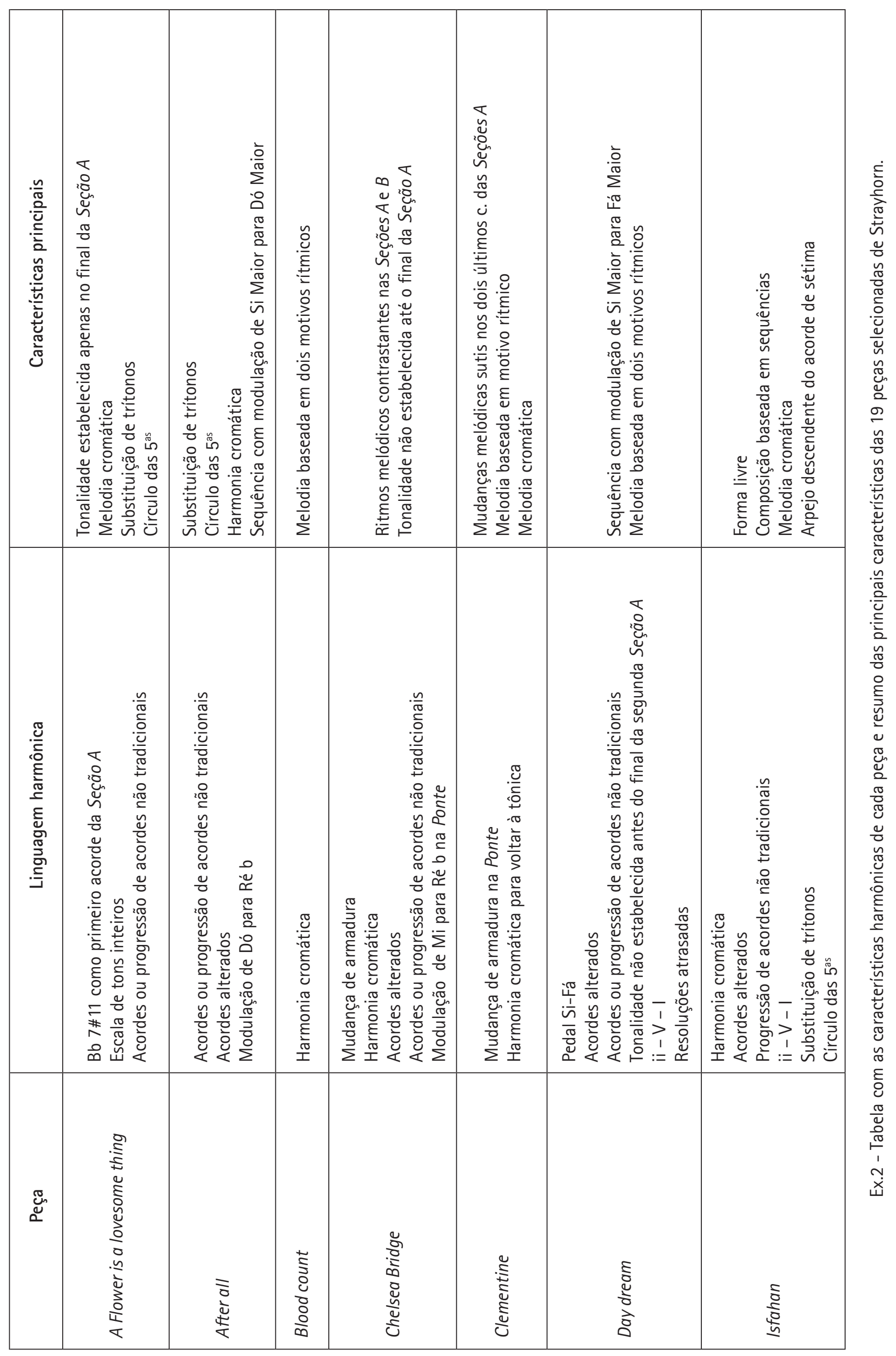




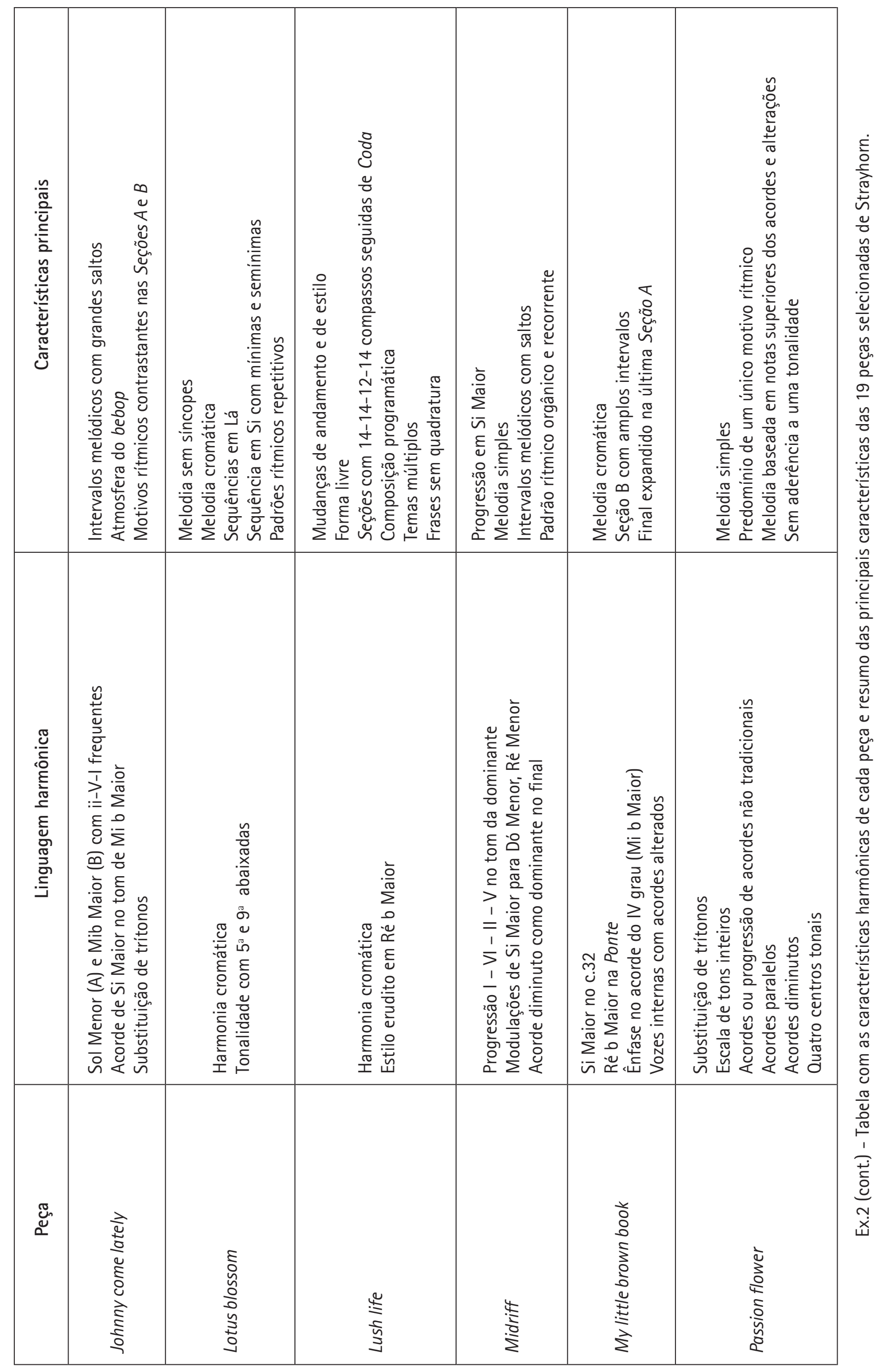




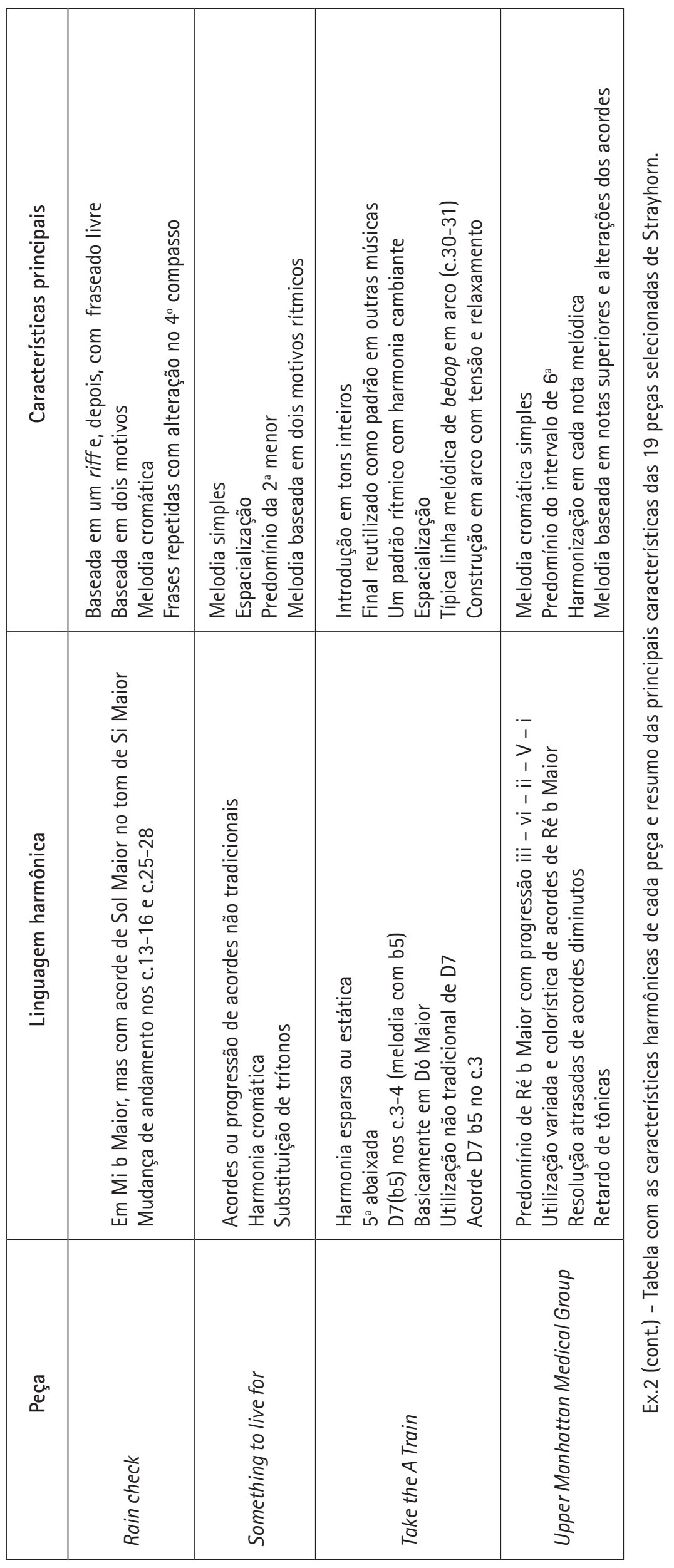




\begin{tabular}{|c|c|}
\hline Ano de composição ou de copyright & No de composições \\
\hline Período Pré-Duke Ellington (1935-1939) & 3 \\
\hline Periodo Duke Ellington (1939-1949) & 2 \\
\hline Conflitos da ASCAP (1941) & 6 \\
\hline Anos de 1942 a 1949 & 3 \\
\hline Década de 1950 & 1 \\
\hline Década de 1960 & 2 \\
\hline
\end{tabular}

Ex.3 - Distribuição das composições selecionadas de Billy Strayhorn por períodos.

\begin{tabular}{|c|c|}
\hline Estilo / andamento & № de composições \\
\hline Balada & 8 \\
\hline Moderado & - \\
\hline Swing & 4 \\
\hline Bright swing & 3 \\
\hline Jazz waltz & 1 \\
\hline Outros & 1 \\
\hline
\end{tabular}

Ex.4 - Distribuição das composições selecionadas de Billy Strayhorn por estilo e/ou andamento.

\begin{tabular}{|l|c|}
\hline \multicolumn{1}{|c|}{ Forma } & No de composições \\
\hline ABA & 1 \\
\hline AABA & 11 \\
\hline ABAC & 2 \\
\hline AABAC & 2 \\
\hline Outras & 1 \\
\hline
\end{tabular}

Ex.5 - Tipos de esquema formal utilizados por Strayhorn nas peças analisadas.

Entretanto, na maioria das vezes, as Seções $A$ não se repetem literalmente, pois Strayhorn preferia trabalhar com sutis diferenças, como pequenas alterações de notas, ritmo ou harmonia, como se observar em Clementine (Ex.6).

Estas mudanças discretas não chegam a caracterizar um estilo de forma livre, como ocorre, por exemplo, na música de Bill Evans (veja artigo às p.21-34 de Per Musi 28). Uma exceção digna de nota ocorre em Lush life, na qual Strayhorn utiliza mudanças mais drásticas, de andamento e atmosfera. Em geral, ele segue mais o princípio de que a função da Seção $B$ é prover contraste à Seção $A$, o que ele realizava com maestria. Para levar o ouvinte a um mundo completamente diferente quando mudava de seções, Strayhorn recorria a modulação para tonalidades distantes, alterações de andamento ou transformação da Ponte em um motivo sequencial para levar a peça de volta ao tom original.

Strayhorn costumava basear suas peças em um ou dois motivos. Alguns exemplos podem ser encontrados em Blood count, Day dream, Johnny come lately, Lotus blossom, Midriff, Passion flower, Raincheck, Something to live for e Take the A Train. 0 Ex.7 mostra o padrão rítmico utilizado em 5 das 6 frases de 4 compassos da 
Seção A de Midriff. Mesmo com esta redundância, a peça não soa repetitiva devido ao artifício usado por Strayhorn na sexta frase da Seção $A$ e em toda a Seção $B$, mesmo considerando que as notas utilizadas, Dós, são também as mesmas nas duas seções.

Em Raincheck, Strayhorn utiliza o seguinte padrão rítmico em 6 das 8 frases de 4 compassos da (Ex.8). Novamente, ele recorre a uma repetição da nota Dó nessas frases.

Um dos padrões rítmicos preferidos por Strayhorn, que recorre em diversas de suas obras, é mostrado no Ex.9. Na maior parte de Passion flower, ele sequencia este padrão em várias alturas. Já em obras de sua maturidade, como Upper Manhattan Medical Group, se tornou mais flexivel na sua abordagem rítmica e deixava a melodia fluir mais independentemente da harmonia
(VAN DE LEUR, 2002, p.163). Ao mesmo tempo, ao utilizar padrões rítmicos repetitivos em muitas de suas composições, Strayhorn variava melodicamente e harmonicamente nas frases restantes, criando novos pontos de interesse para o ouvinte.

Mas considerando sua adoção consistente da forma tradicional e a repetição de esquemas rítmicos padronizados, o que tornaria a música de Strayhorn peculiar? Para Walter van de Leur, há principalmente dois procedimentos. Primeiro, a maneira como ele recorre a uma grande variedade de motivos harmônicos, rítmicos e melódicos para criar coesão e unidade (VAN DE LEUR, 2002, p.75). Segundo, a utilização de estruturas que formam um arco obtido com um gradual aumento e relaxamento da tensão (VAN DE LEUR, 1999. p.1084), o que é bem exemplificado em Take the A Train.
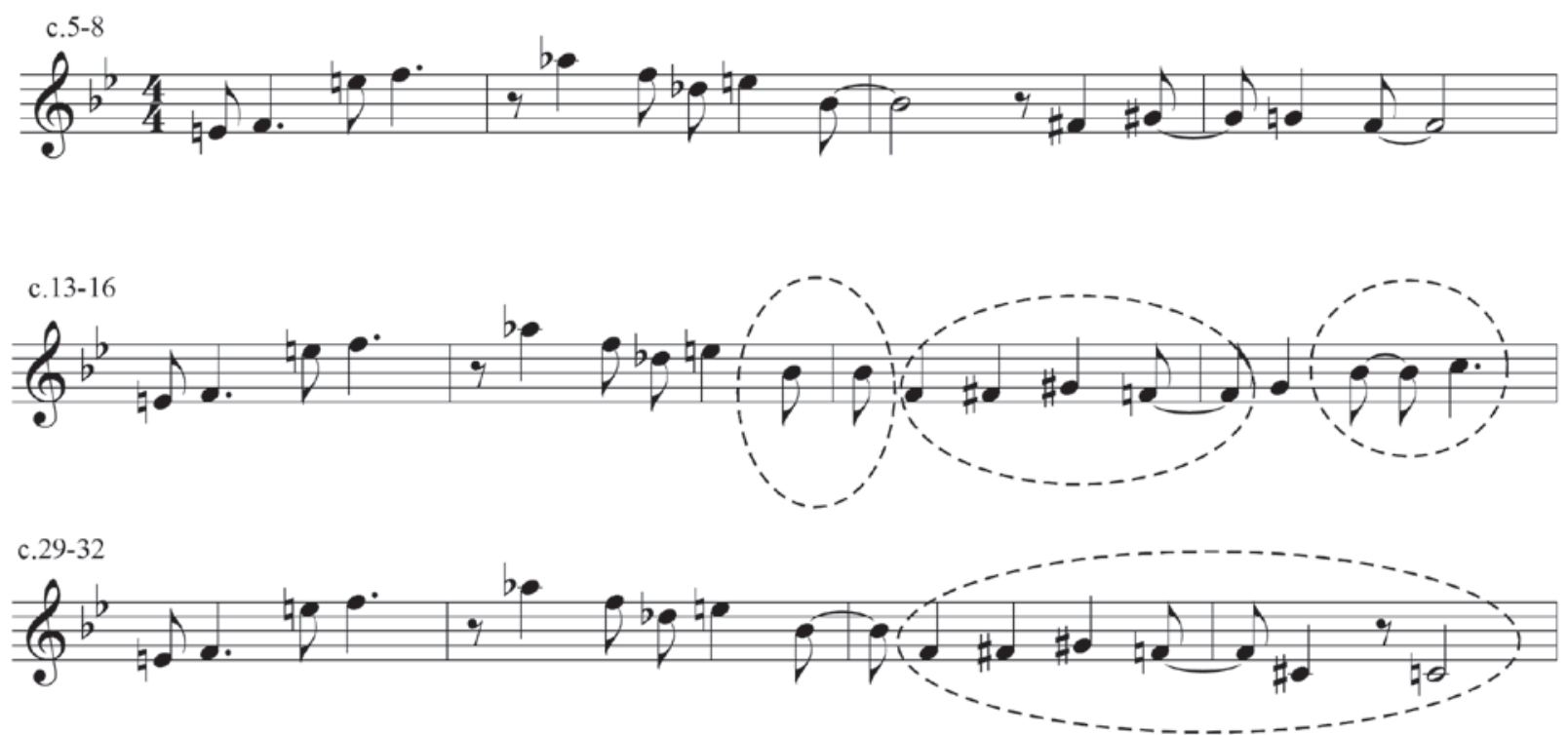

Ex.6 - Diferenças sutis nas repetições das Seções A em Clementine de Billy Strayhorn.

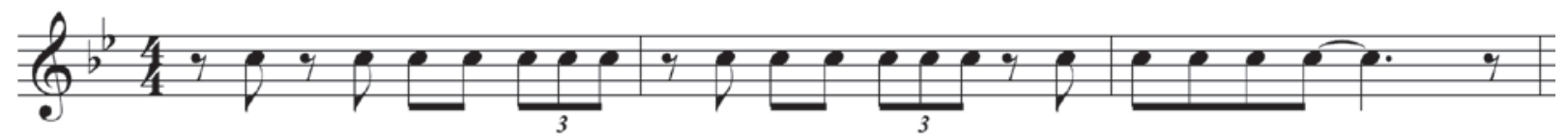

Ex.7 - Motivo rítmico utilizado por Strayhorn em 5 das 6 frases de 4 compassos da Seção A de Midriff.

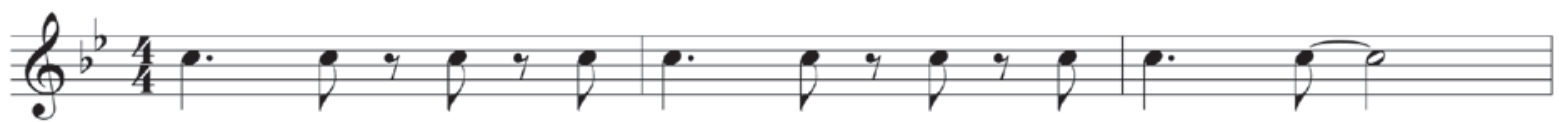

Ex.8 - Motivo rítmico utilizado por Strayhorn em 6 das 8 frases de 4 compassos de Raincheck. 


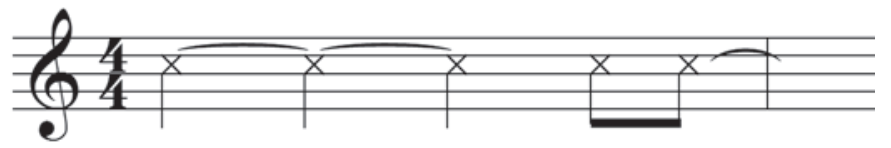

Ex.9 - Um dos motivos rítmicos mais utilizados por Strayhorn.

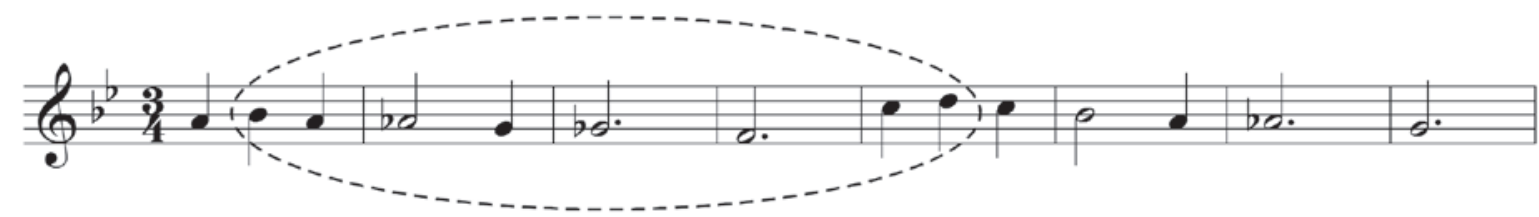

Ex.10 - Utilização de 8 notas (75\%) do total cromático no tema de Lotus blossom de Strayhorn.
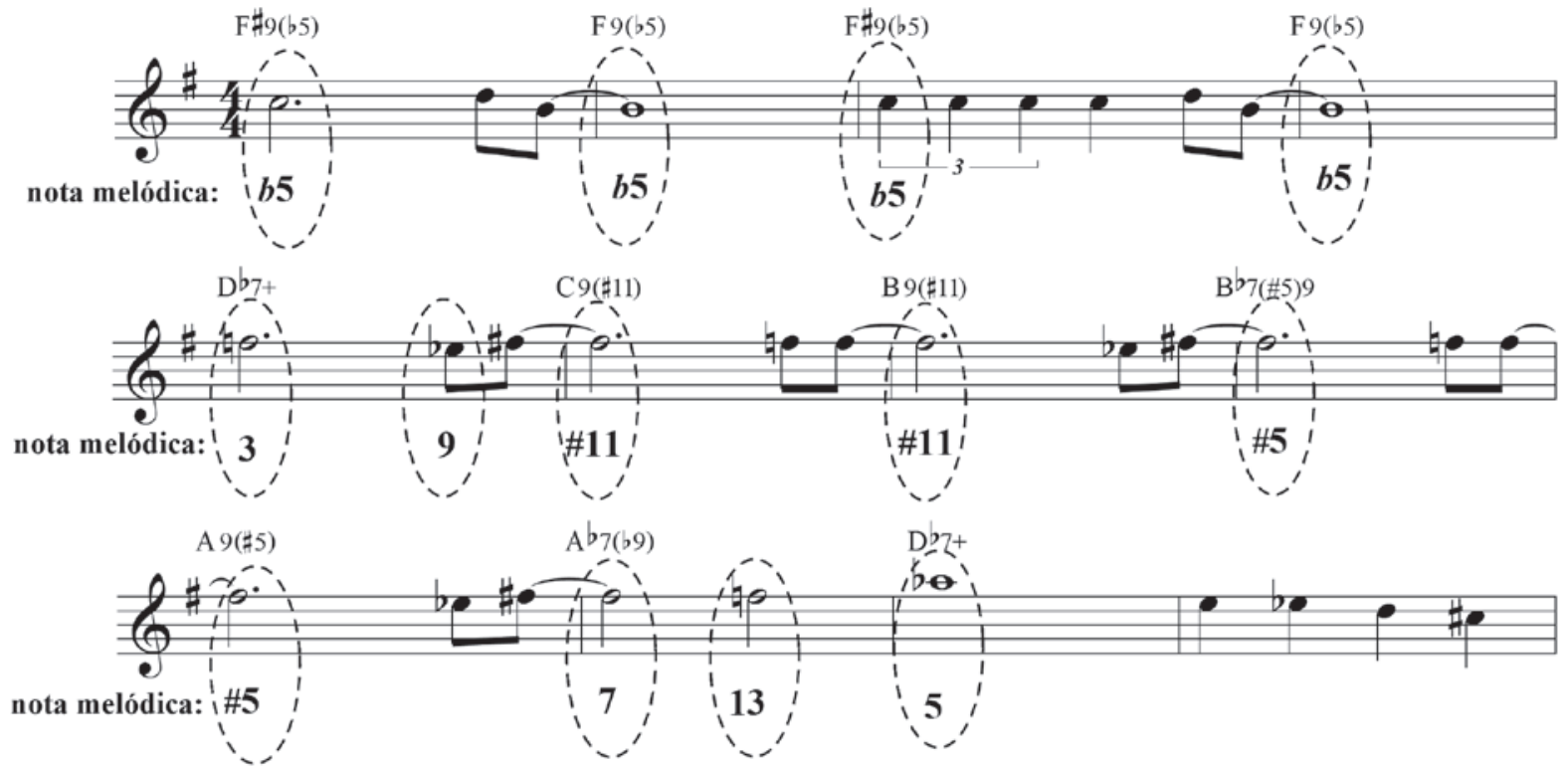

Ex.11- Coincidência da nota melódica com a nota superior do acordes em Passion flower de Strayhorn.

Outro elemento musical que Strayhorn usa é o cromatismo melódico, especialmente com ênfase no intervalo de segunda menor. Dez das melodias analisadas (A Flower is a lovesome thing, After all, Clementine, Isfahan, Lotus blossom, Lush life, My little brown book, Rain check, Something to live for e Upper Manhattan Medical Group) podem ser classificadas como basicamente cromáticas. Em outro exemplo, $A$ Flower is a lovesome thing, ele emprega 11 das 12 notas da escala cromática. Já nos primeiros oito compassos de Lotus blossom ele emprega 8 notas cromáticas, o que equivale a $75 \%$ do total cromático (Ex.10).
Outra de suas estratégias no tratamento melódico é o uso das notas superiores dos acordes como notas-guia das melodias como ocorre, por exemplo, nas frases de Passion flower mostradas no Ex.11.

Muitas vezes, Strayhorn conduzia uma voz interna para criar um intervalo dissonante com uma ou mais notas do acompanhamento, mesmo que a melodia se situasse à distância de uma nona menor ou maior acima das notas do acorde (VAN DE LEUR, 1999, p.75-76). Um bom exemplo deste procedimento ocorre nos primeiros seis compassos de My little brown book, mostrado no Ex.12, 
em que pode-se observar as alterações nos acordes para mudar a cor do som e prover o contraponto interno cromático, típico de seu estilo.

Apesar de seu treinamento formal em harmonia erudita, que pode ser amplamente apreciado em Tin Pan Alley, Strayhorn se preocupava mais com a sonoridade resultante do que com regras harmônicas do meio acadêmico. Mas, à medida em que foi amadurecendo, ele passou a utilizar menos acordes inesperados, a exemplo de Something to live for (VAN DE LEUR, 2002, p.28), diferentemente do que fazia nas suas peças de mocidade. Independentemente deste processo de suavização harmônica ao longo da carreira de Strayhorn, todas as peças analisadas aqui contem progressões harmônicas ou acordes não tradicionais.

Em Strayhorn observa-se claramente uma tendência de associar tonalidades com bemóis a sonoridades mais opacas e sem pressa. Por outro lado, ele relaciona as tonalidades com sustenidos às atmosferas mais brilhantes. 0 Ex.13 mostra a ocorrência de tonalidades em suas peças analisadas neste estudo.

Pode-se observar ainda nesse exemplo que Strayhorn não escrevia muito em tons menores, embora uma de suas peças mais importantes, Blood count, comece em Ré Menor e oscile entre esta tonalidade e seu homônimo,
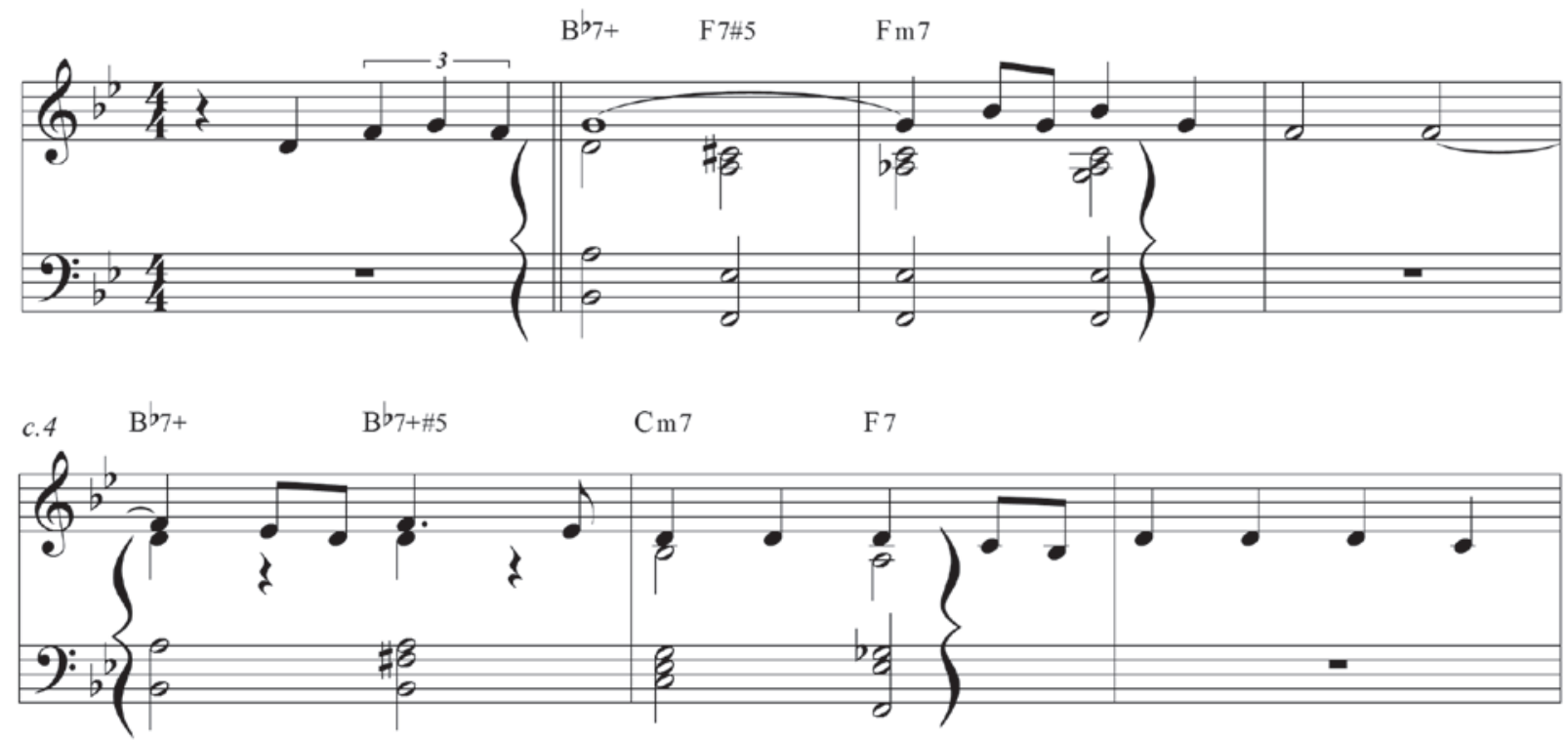

Ex.12 - Voicing de Strayhorn em My little brown book, criando dissonâncias entre as vozes internas.

\begin{tabular}{|c|c|}
\hline Tonalidade & No de composições \\
\hline Dó Maior & 2 \\
\hline Réb Maior & 5 \\
\hline Ré Maior & 1 \\
\hline Mi b Maior & 1 \\
\hline Fá Maior & 1 \\
\hline Sol Maior & 1 \\
\hline Sib Maior & 4 \\
\hline Ré Menor / Maior & 1 \\
\hline Sol Menor & 1 \\
\hline
\end{tabular}

Ex.13 - Ocorrências de tonalidades nas obras selecionadas de Strayhorn. 
Ré Maior. Mas isto se explica pelo contexto significativo de sua vida, pois escreveu esta obra enquanto estava morrendo de câncer, como mencionado anteriormente, o que é refletido na alternância entre as tonalidades menor e maior. Além disso, sobreposta a esta incerteza harmônica, a melodia cromática que ele utiliza narra um quadro da morte iminente.

Assim como ocorre na música de Bill Evans (veja artigo às p.21-34 do volume 28 de Per Musi), as armaduras de clave não têm um papel fundamental na música de Strayhhorn. Diversas peças, como A Flower is a lovesome thing. Chelsea bridge, Lush life, Passion flower e Blood count são famosas pela ambiguidade tonal que ele estabelece já desde o início. É difícil perceber essas peças como tonais, quando começamos a ouvi-las, uma vez que suas tonalidades só são definidas mais tarde, como no final da Seção A, como ocorre em A Flower is a lovesome thing e Daydream. Um dos procedimentos que ele utiliza para obter essa ambiguidade é recorrer à escala de tons inteiros, prática que chegou ao jazz pela música dos compositores impressionistas, especialmente Debussy e Ravel, muito admirados por Strayhorn. Por exemplo, na melodia e movimento harmônico dos três primeiros compassos de Chelsea Bridge, podem-se ouvir ecos do segundo movimento das Valsas nobres e sentimentais (1911) de Ravel. (VAN DE LEUR, 2002, p.51). Strayhorn argumentava que não havia uma influência direta nesse caso e que nunca tinha ouvida aquela obra do mestre francês (ULANOV, 1946, p. 225). Apesar disto, a harmonia nos quatro primeiros compassos dessa peça é bem típica da harmonia não-funcional de Debussy.

A harmonia cromática e a substituição de trítonos são elementos típicos de Strayhorn. Um bom exemplo desta utilização ocorre em Passion flower, cuja progressão harmônica das Seções $A$ e $B$ nada tem de tradicional: ${ }^{1}$

Seção A: / F\#9 b5 / F9 b5 / F\#9b5 / F9 b5 / E7\#5(b9) Eb7 / D7 D7b9 / G69 / G69 /

Seção B: / Dbmaj7 / C9\# 11 / B9\# 11 / Bb7\#5(b9) / A9\#5 / Ab7b9 / Dbmaj / Dbmaj /
Outro exemplo, retirado da Seção B de After all confirma, assim como todas as outras peças analisadas neste artigo, a utilização de harmonia cromática:

Seção B: / Fmaj7 / E7 / Eb6 / Am7 D7 / Db6 / C7 / B13 Ab13 / G13 /

Algumas das passagens cromáticas mais interessantes ocorrem nas pontes entre seções, que Strayhorn utiliza formalmente para chegar a tonalidades remotas ou ainda, para retornar à tônica de uma tonalidade remota. Esses dois elementos ocorrem em Chelsea Bridge, na qual a tonalidade passa de Ré bemol Maior para Mi Maior imediatamente. Ao mesmo tempo, a Ponte permite a modulação reversa, de Mi Maior para Ré bemol Maior. (VAN DE LEUR, 1999, p.1083). A Seção B de Daydream pode ser descrita como uma modulação melódica sequencial de Si bemol Maior para Fá Maior utilizando harmonia cromática e a tradicional progressão ii - V - I. Já em Raincheck, o centro tonal é Mi bemol Maior, mas a Seção $B$ é em Sol Maior, cuja sensivel Fá \# ocorre apenas em quatro compassos, mas o suficiente para desnortear os ouvintes em relação a qual direção Strayhorn os está levando.

Acordes alterados com a finalidade de produzir cores específicas ocorrem apenas em em cada uma das 19 peças aqui selecionadas. Como mencionado antes, Strayhorn utiliza esses acordes para extrair notas para compor suas melodias. Nessas melodias, já com a mente focada no arranjo e designação instrumental, escolhe as notas que se tornam muito relevantes na sonoridade final que desejava obter. Os músicos de jazz são conhecidos pelo prazer que tem de substituir os acordes originais de uma peça. Entretanto, assim como ocorre na música de Bill Evans (veja p.21-34 no volume 28 de Per Musi), as composições de Strayhorn são tão bem acabadas que ao substituir acordes em sua música, geralmente perde-se parte de seu potencial colorístico, ao invés de aumentá-lo. Comparado aos seus contemporâneos, a abordagem da harmonia por Strayhorn nos seus arranjos e composições (fundamental no que ele chamava de "som") estava um passo à frente e mereceria um estudo à parte. 


\section{Referências}

CARNER, Gary. Billy Strayhorn: man, music, and influence. Sonneck Society Bulletin. v.17, n.2, 1991. p.48-52.

COSS, Bill. Billy Strayhorn Interviewed by Bill Coss. In: Duke Ellington Reader. Mark Tucker ed, New York: Oxford University Press, 1993.

ELLINGTON, Edward Kennedy. Music is my mistress. New York: Da Capo Press, 1973.

GIDDINS, Gary; DE VEAUX, Scott. Jazz. New York: W. W. Norton \& Co., 2009.

HAIDU, David. Lush Life: A Biography of Billy Strayhorn. New York: Farrar Straus Giroux, 1996.

LAMBERT, Eddie. A Listener's guide: Duke Ellington (Lanham, MD: Scarecrow Press, 1999.

LORD, Tom. The Tune Index-The Jazz Discography. West Vancouver, B.C., Canadá: Lord Music Reference, 2002.

MURRAY, J. William (Bill) Murray. Billy's touch: an analysis of the

compositions of Bill Evans, Billy Strayhorn, and Bill Murray. Towson, Maryland, EUA: Towson University: 2011 (Dissertação de Mestrado).

NICHOLSON, Stuart. A Portrait of Duke Ellington: reminiscing in tempo. London: Sidwick \& Jackson, 1999.

REED, Bill, Hot from Harlem: Twelve African American entertainers, 1890-1960. Ed. rev. Jefferson, N.C., EUA: Mc Farland \& Company, 2010.

STRAYHORN, Billy. Billy Strayhorn arranging hints. Music \& Rhythm. Maio, 1942.

ULANOV, Barry. Duke Ellington. New York: Creative Age Press, 1946.

VAN DE LEUR, Walter. Strayhorn, William Thomas ("Billy"). International Dictionary of Black Composers. Samuel A. Floyd, Editor. Chicago: Fitzroy Dearborn, 1999.

VAN DE LEUR, Walter. Something to live for: the music of Billy Strayhorn. New York: Oxford University Press, 2002.

\section{Nota}

10 sinal / indica barras de compasso. Assim, dois acordes entre dois destes sinais indicam que os mesmos são tocados o $1^{\circ}$ e $3^{\circ}$ tempos do compasso.

0 pianista, compositor e arranjador J. William (Bill) Murray graduou-se com o Bacharelado em Música e o Mestrado em Música (Composição e Jazz) pela Towson University in Towson, Maryland, EUA. Além disso, obteve o MBA em Economia com honra pela Kellogg Graduate School of Management e o Bacherelado em Economia com honra especial pela University of Colorado. Como performer, atua na região de Baltimore como solista e arranjador para grupos de jazz. Gravou suas obras em dois CDs Billy's touch e Moving On. Atualmente, é Presidente da Baltimore Chamber Jazz Society e membro diretor da Towson University Foundation, University System of Maryland Foundation e Center Stage Theater.

Fausto Borém é Professor Titular da UFMG, onde criou o Mestrado e a Revista Per Musi. Pesquisador do CNPq desde 1994, publicou dois livros, três capítulos de livro, dezenas de artigos sobre práticas de performance e suas interfaces (composição, análise, musicologia, etnomusicologia da música popular e educação musical) em periódicos nacionais e internacionais, dezenas de edições de partituras e recitais nos principais eventos nacionais e internacionais de contrabaixo. Recebeu diversos prêmios no Brasil e no exterior como solista, teórico, compositor e professor. 